\title{
Effect of Gosha-Jinki-Gan on Levels of Specific mRNA Transcripts in Mouse Testes after Busulfan Treatment
}

\author{
Ning $Q u^{1,2, *,+}{ }^{\mathbb{C}}$, Kenta Nagahori ${ }^{2, \dagger}$, Miyuki Kuramasu ${ }^{2}$, Yuki Ogawa ${ }^{2}$, Kaori Suyama ${ }^{1}$, \\ Shogo Hayashi ${ }^{1}$ (D), Kou Sakabe ${ }^{1}$ and Masahiro Itoh ${ }^{2}$ \\ 1 Department of Anatomy, Division of Basic Medical Science, Tokai University School of Medicine, \\ Kanagawa 259-1193, Japan; suyama@is.icc.u-tokai.ac.jp (K.S.); sho5-884@umin.ac.jp (S.H.); \\ sakabek@tokai-u.jp (K.S.) \\ 2 Department of Anatomy, Tokyo Medical University, Tokyo 160-8402, Japan; kenta-n@tokyo-med.ac.jp (K.N.); \\ kitaoka@tokyo-med.ac.jp (M.K.); yogawa@tokyo-med.ac.jp (Y.O.); itomasa@tokyo-med.ac.jp (M.I.) \\ * Correspondence: quning@tokai.ac.jp or quning@tokyo-med.ac.jp; Tel.: +81-4-6393-1121; \\ Fax: +81-4-6393-1517 \\ $\dagger$ These authors contributed equally to this work.
}

Received: 30 September 2020; Accepted: 17 October 2020; Published: 19 October 2020

\begin{abstract}
With the increase in survival rates of cancer patients in recent years, infertility caused by anticancer treatments has become a significant concern for cancer survivors. Some studies have suggested that Sertoli cells play a key role in mediating testicular immunology in busulfan-induced aspermatogenesis. We recently demonstrated that Gosha-jinki-gan (TJ107), a traditional Japanese medicine, can completely recover injured spermatogenesis in mice 60 days after busulfan injection. In the present study, we sought to examine the levels of mRNA transcripts encoding markers of 25 Sertoli cell-specific products and 10 markers of germ cell differentiation. Our results demonstrated that only supplementation of TJ107 at day 60 after busulfan injection could significantly recover the increase in five mRNA species (Amh, Clu, Shbg, Testin, and Il1a) and the decrease in four mRNA species (Aqp8, CST9, Wnt5a, and Tjp1) in response to Busulfan (BSF) at day 120, with the increase of all examined spermatogenic markers.
\end{abstract}

Keywords: oriental medicine; aspermatogenesis; specific mRNA transcript; anticancer treatment

\section{Introduction}

Busulfan (BSF; 1,4-butanediol dimethanesulfonate) is used as both a chemotherapeutic drug in the treatment of various malignancies [1,2] and an immunosuppressive drug in hematopoietic stem cell transplantation [1]. BSF treatment has been extensively shown to disrupt spermatogenesis by damaging germ cells and Sertoli cells [3,4]. Previous studies demonstrated that BSF may induce germ cell apoptosis through loss of c-kit signaling in a Fas/FasL- and p53-independent manner [5]. In BSF-induced apoptosis, p53 is a key protein through reactive oxygen species (ROS)-dependent activation of the extracellular signal-regulated kinase/p38 pathway, and decreased concentrations of deacetylated p53 result in spermatogonial cell resistance to apoptosis [6]. The in vivo and in vitro study showed that spermidine/spermine N1-acetyltransferase 2 (Sat2) is present in testicular Sertoli cells and that its expression is significantly increased by BSF treatment. Furthermore, upregulation of Sat2 by BSF alters the growth and function of Sertoli cells and causes male infertility [7]. Additionally, it has been demonstrated that BSF-induced spermatogenic cell damage upregulates tumor necrosis factor $\alpha$ and macrophage chemotactic protein 1 expression in Sertoli cells and facilitates macrophage infiltration into the testes [8]. These damaged germ cells in BSF-treated mice release endogenous Toll-like receptor (TLR) ligands to activate TLR2 and TLR4 in Sertoli cells, thus initiating endogenous inflammation in the testes $[8,9]$. 
The side effects of BSF include gonadal dysfunction amenorrhea and azoospermia in humans [10-12], and information on therapy for BSF-induced male infertility is limited. In mice, we previously found testicular weight loss, seminiferous tubule atrophy, spermatogenic cell degeneration, and apoptosis 60 days after BSF treatment $(40 \mathrm{mg} / \mathrm{kg})$ [13]. As a result of the limited information on therapy for BSF-induced male infertility, we attempted to determine the effects of several oriental Japanese medicines, such as Gosha-jinki-gan, Hachimi-jio-gan, and Hochu-ekki-to, on BSF-induced infertility [9,14]. We demonstrated that Gosha-jinki-gan (TJ107) was able to completely normalize testicular immunopathology and to promote recovery from severe aspermatogenesis following BSF treatment in mice [9]. Male 4-week-old C57BL/6j mice were administered a single intraperitoneal injection of BSF and were then fed a normal diet for 60 days and then a TJ107 or TJ107-free (normal) diet for another 60 days. After BSF treatment, the epididymal sperm count progressively decreased from 60 days $\left(1.575 \pm 0.308 \times 10^{5}\right.$ cells $)$ to 120 days $\left(0.217 \pm 0.019 \times 10^{5}\right.$ cells $)$ in the normal diet group. In the T107 diet group, dramatic recovery of these variables (21.680 $\pm 1.700 \times 10^{5}$ cells) was observed at 120 days, which was similar to the results of normal mice (20.500 $\pm 2.462 \times 10^{5}$ cells) [9]. In the current study, we examined whether TJ107 could recover spermatogenesis at 120 days following administration with BSF. We further examined the markers of Sertoli cell-specific products and germ cell differentiation in order to clarify the mechanism of the different therapeutic effects of TJ107 at different times of administration on BSF-induced infertility.

\section{Materials and Methods}

\subsection{Animals}

C57BL/6J male mice at 4 weeks of age (weighing $16 \mathrm{~g}-18 \mathrm{~g}$ ) were purchased from SLC (Shizuoka, Japan) and were kept in the Laboratory Animal Center of Tokyo Medical University (Tokyo Medical University Animal Committee; no. S27001-01042016 (1 April 2015) and no. H28016-01042017 (1 April 2016)) and the Animal Laboratory of Support Center for Medical Research and Education, Tokai University (Tokai University Animal Committee; no. 171058-01042017 (1 April 2017)). The mice were maintained at a temperature of $22{ }^{\circ} \mathrm{C}-24^{\circ} \mathrm{C}$ and a relative humidity of $50 \%-60 \%$, with a 12-h light-dark cycle.

\subsection{Preparation of a Gosha-Jinki-Gan Diet}

Gosha-jinki-gan (TJ107) (extract granules in powdered form; no. 2120107030) was manufactured by Tsumura \& Co. (Tokyo, Japan) according to Japanese and international manufacturing guidelines. TJ107 is a standardized prescription medicine containing 10 crude components: Rehmanniae radix, 5 g; Achyranthis radix, 3 g; Corni fructus, 3 g; Dioscoreae rhizome, 3 g; Plantaginis semen, 3 g; Alismatis rhizome, $3 \mathrm{~g}$; Hoelen, $3 \mathrm{~g}$; Moutan cortex, $3 \mathrm{~g}$; Cinnamomi cortex, $1 \mathrm{~g}$; and processed Aconite tuber, $1 \mathrm{~g}$. A TJ107 diet was prepared as a mouse diet (standard diet; $23.1 \%$ crude protein $(w / w), 5.1 \%$ crude fat, $5.8 \%$ crude ash, $2.8 \%$ crude fiber, and $55.3 \%$ nitrogen-free extract and mineral mixture; Oriental Yeast Co., Ltd., Tokyo, Japan) containing 5.4\% (w/w) TJ107 extract.

\subsection{Experimental Design}

BSF (Sigma, St. Louis, MO, USA), $40 \mathrm{mg}$, was first dissolved in $1 \mathrm{~mL}$ dimethyl sulfoxide (DMSO; Sigma). The mice were weighed and given a single injection of BSF $(16 \mu \mathrm{L}-18 \mu \mathrm{L})$ diluted in $100 \mu \mathrm{L}$ distilled water to achieve a final concentration of $40 \mathrm{mg}$ per $\mathrm{kg}$ body weight.

The study mice were randomly divided into the following five groups: group I: control group $(n=15)$, mice that received a single intraperitoneal injection of DMSO and were fed the standard diet for 120 days after injection; group II: control + TJ107 group $(n=15)$, mice that received a single intraperitoneal injection of DMSO and were fed the TJ107 diet for 120 days after injection; group III: BSF group $(n=15)$, mice that received a single intraperitoneal injection of BSF and were fed the standard diet for 120 days after injection; group IV: BSF day $0+$ TJ107 group $(n=15)$, mice that received a single intraperitoneal injection of BSF and were fed the TJ107 diet for 120 days after injection; 
and group V: BSF day $60+$ TJ107 group $(n=15)$, mice that received a single intraperitoneal injection of BSF and were fed the standard diet for 60 days after injection and then the TJ107 diet for the remaining 60 days, until 120 days after injection. The general condition, food intake, and body weight were documented for all mice at 10-day intervals from 60 days to 120 days after injection. The experimental study protocols were performed in accordance with the guidelines of the National Institutes of Health and were approved by the Tokyo Medical University Animal Committee (no. S27001 and no. H28016) and the Tokai University Animal Committee (No. 171058).

At 120 days after injection, to assess in vivo fertilization ability, we cross-mated mice from each group $(n=5)$ with normal C57BL/6j female mice (8-10 weeks of age; SLC, Shizuoka, Japan) at a male-to-female ratio of 1:2 in a cage for 1 month and determined the fertility rate for each group.

To examine the effect of TJ107 with BSF on spermatogenesis, the remaining mice from each group $(n=5)$ were deeply anesthetized with pentobarbital $(65 \mathrm{mg} / \mathrm{kg}$ body weight), the testes were removed for gravimetry, and epididymides were immediately removed to perform the epididymal spermatozoa count 120 days after injection. Furthermore, to clarify the causality of partially recovered spermatogenesis 60 days after injection in group I, group III, and group IV, mice $(n=5)$ were deeply anesthetized and the testes and epididymides were removed for examination 60 days after injection.

\subsection{Histological Examination of the Testes}

The testes of mice from each group $(n=5)$ were fixed whole with Bouin's solution and embedded in plastic (Technovit7100; Kulzer \& Co., Wehrheim, Germany). Sections (5 $\mu \mathrm{m})$ were obtained at 15-20- $\mu \mathrm{m}$ intervals and were stained with Gill's hematoxylin and 2\% eosin Y (Muto PC, Tokyo, Japan) for observation under light microscope.

\subsection{Analysis of the Specific mRNA Species in Testes Using Real-Time RT-PCR}

The testes from mice in each group $(n=5)$ were examined. Total RNA was purified from each fresh tissue sample using TRIZOL reagent (Invitrogen Corp., Carlabad, CA) according to the manufacturer's protocol, and its concentration was calculated from the extinction at $260 \mathrm{~nm}$, as determined spectrophotometrically. For cDNA synthesis, $5 \mu \mathrm{g}$ of total RNA was reverse-transcribed with a High Capacity cDNA Archive Kit (PE Applied Biosystems, Foster City, CA, USA) according to the standard protocol carried out with an iCycler Thermal Cycler (Bio-Rad, Hercules, CA, USA). The mixtures were stored at $-80{ }^{\circ} \mathrm{C}$ until analysis. Real-time RT-PCR was performed on $2.5-\mu \mathrm{g}$ cDNA using the validated SYBR Green gene expression assay in combination with SYBR Premix Ex $\operatorname{Taq}^{\mathrm{TM}}$ (TaKaRa, Bio Inc., Ohtsu, Japan) for the 10 germ cell genes (Stra8, Spo11, Tnp1, cKit, Gfra1, Vasa, Boll, Crem, Prm1, and Acrosin), 25 Sertoli cell genes (Amh, Aqp8, Cond2, Clu, Cldn11, Cst12, Cst9, Dhh, Espn, Fshr, Fyn, GATA1, Il1a, Inhba, Inhbb, Msi1, Rhox5, Testin, Shbg, Spata2, Sox9, Tjp1, Trf, Wt1, and $(n t 5 a)$, and GAPDH as an internal control, respectively, with forward and reverse primers described previously [15-19] and was synthesized from Hokkaido System Science Co., Ltd. (Sapporo City, Hokkaido, Japan). Quantitative real-time PCR was performed in duplicate with the Thermal Cycler Dice Real-time System TP800 (TaKaRa), and the thermal profile used for amplification was $95^{\circ} \mathrm{C}$ for $30 \mathrm{~s}$ followed by 40 cycles of $95^{\circ} \mathrm{C}$ for $10 \mathrm{~s}, 60^{\circ} \mathrm{C}$ for $10 \mathrm{~s}$, and $72{ }^{\circ} \mathrm{C}$ for $10 \mathrm{~s}$. The Thermal Cycler Dice Real-time System software (TaKaRa) was used to analyze the data, and the comparative $\mathrm{C}_{\mathrm{t}}$ method $\left(2 \Delta \Delta C_{t}\right)$ was used to quantify the gene expression levels. The results are expressed relative to $G A P D H$. The relative mRNA intensity was calculated, and the expression in the control group for each point was normalized to 1 . The data are presented as mean \pm standard deviation. Primers used in this analysis are shown in Table 1. 
Table 1. Primers used for real-time RT-PCR.

\begin{tabular}{|c|c|c|}
\hline Genes & Forward Primer & Reverse Primer \\
\hline GAPDH & TGTGTCCGTCGTGGATCTGA & TTGCTGTTGAAGTCGCAGGAG \\
\hline \multicolumn{3}{|l|}{ Sertoli Cell } \\
\hline Amh & TCCTACATCTGGCTGAAGTGATATGGG & AGGTTCTGTGTGCCCCGCAG \\
\hline Aqp8 & GCTGGCAGTCACAGTGATCGGA & CCTGGACGATGGCAAAGGCTG \\
\hline Ccnd2 & GGAACCTGGCCGCAGTCACC & AATCATCGACGGCGGGTACATG \\
\hline $\mathrm{Clu}$ & CCACGCCATGAAGATTCTCCTGC & СTCCCTGGACGGCGTTCTGA \\
\hline Cldn11 & TCACAACGTCCACCAATGACTG & GGCACATACAGGAAACCAGATG \\
\hline Cst12 & GGATGACGATTTTGCCTACAAGTTCCT & ТTСТСТСТССТGGACСТTССТGСА \\
\hline Cst9 & GATATTTGCCССTTTCAGGAGAGCC & AGAGAAGTACGTGACCAGTCCATGGG \\
\hline Dhh & GGCGCAGACCGCCTGATG & AAGGCACGGCCTTCGTAGTGG \\
\hline Espn & GCTTCTGGTCGGGCATTACCCT & GTGTCATGCCGTCTTGGGCG \\
\hline Fshr & GGCCAGGTCAACATACCGCTTG & TGCCTTGAAATAGACTTGTTGCAAATTG \\
\hline Fyn & GAAGCGGCCCTGTATGGAAGGTT & TGTGGGCAGGGCATCCTATAGC \\
\hline GATA1 & ATGGTCAGAACCGGCCTCTCATC & GAGCTTGAAATAGAGGCCGCAGG \\
\hline Illa & TTGGTTAAATGACCTGCAACA & GAGCGCTCACGAACAGTTG \\
\hline Inhba & CATGGAGCAGACCTCGGAGATCA & TGGTCCTGGTTCTGTTAGCCTTGG \\
\hline $\operatorname{Inh} b b$ & GAGCGCGTCTCCGAGATCATCA & CGTACCTTCCTCCTGCTGCCCTT \\
\hline Msi1 & TCACTTTCATGGACCAGGCGG & GTTCACAGACAGCCCССССа \\
\hline Rhox 5 & AGGTTCGCCCAGCATCGACTG & GCCGCAGCCCTCCTGATCTT \\
\hline Testin & AAAGACAATGGCGGCCTCGc & GGCCCCACTTTAGCCACTGCC \\
\hline Shbg & GACATTCCCCAGCCTCATGCA & TGCCTCGGAAGACAGAACCACG \\
\hline Spata2 & GCCGTGTGGGCCTGTGCTT & TTCCCCAAATCAAACCCAAGGG \\
\hline Sox9 & CGCGGAGCTCAGCAAGACTCTG & TGTCCGTTCTTCACCGACTTCCTC \\
\hline Tjp1 & GCGGAGAGAGACAAGATGTCCGC & CTCTGAAAATGAGGATTATCTCTTCCACCA \\
\hline $\operatorname{Trf}$ & CAAATGCATCAGCTTCCGTGACC & CGGCATCGTACACCCAACCC \\
\hline Wt1 & GCTCCAGCTCAGTGAAATGGACAGAA & GGCCACTCCAGATACACGCCG \\
\hline Wnt5a & CTGCTTCTACCATGCGTTTGCTGG & GCCATGGGACAGTGCGGC \\
\hline \multicolumn{3}{|l|}{ Germ Cell } \\
\hline Tnp1 & GGCGATGATGCAAGTCGCAA & CCACTCTGATAGGATCTTTGGCTTTTGG \\
\hline Spo11 & CGCGTGGCCTCTAGTTCTGAGG & GGTATCATCCGAAGGCCGACAGAAT \\
\hline Stra8 & GAAGGTGCATGGTTCACCGTGG & GCTCGATGGCGGGCCTGTG \\
\hline cKit & GCATCACCATCAAAAACGTG & GATAGTCAGCGTCTCCTGGC \\
\hline Gfra1 & CAGTTTTCGTCTGCTGAGGTTG & TCTGCTCAAAGTGGCTCCAT \\
\hline Vasa & AGTATTCATGGTGATCGGGAGCAG & GCAACAAGAACTGGGCACTTTCCA \\
\hline Boll & AACCCAACAAGTGGCCCAAGATAC & CTTTGGACACTCCAGCTCTGTCAT \\
\hline Crem & TTCTTTCACGAAGACCСТCA & TGTTAGGTGGTGTCCCTTCT \\
\hline Prm1 & TCCATCAAAACTCCTGCGTGA & AGGTGGCATTGTTCCTTAGCA \\
\hline Acrosin & TGTCCGTGGTTGCCAAGGATAACA & AATCCGGGTACCTGCTTGTGAGTT \\
\hline
\end{tabular}

\subsection{Epididymal Spermatozoa Count}

Epididymal spermatozoa were recovered from both epididymes of mice in each group $(n=5)$. Briefly, the epididymides were dissected out and cut into six pieces in phosphate-buffered saline (PBS). All pieces were gently pipetted and then passed through a stainless-steel mesh. The epididymal spermatozoa were harvested by centrifugation at $400 \times g$ for $10 \mathrm{~min}$ and resuspended in $5 \mathrm{~mL}$ of PBS after washing three times with PBS.

\subsection{Statistical Analysis}

ANOVA and Tukey-Kramer post hoc test were used to analyze the differences between the multiple groups. A $p$-value $<0.05$ was considered statistically significant.

\section{Results}

3.1. Supplemented TJ107 Significantly Recovered Spermatogenesis and Levels of mRNA Transcripts Encoding Markers of Germ Cell Differentiation in the BSF-Treated Group V Mice at Day 120

Following BSF treatment, the mean body weight of the mice in the BSF-treated groups (groups III, IV, and V) were significantly lower than that of control mice (group I) at the end of the experiment (day 120), regardless of TJ107 supplementation (Table 2). In contrast, only the group V mice showed 
significant and almost complete recovery of testicular weight, epididymal spermatozoa counts, and fertility rate to the levels found in group I (Table 2). The mice in group IV also showed significant recovery in their testicular weights, spermatozoa count, and fertility rate compared to the mice in group III, although they did not return to the control levels in group I (Table 2).

Table 2. Testicular weights and epididymal spermatozoa count in each group at day 120 .

\begin{tabular}{cccccc}
\hline Groups & I & II & III & IV & V \\
\hline Body weight $(\mathrm{g})$ & $33.310 \pm 0.917$ & $33.905 \pm 1.117$ & $26.982 \pm 2.103^{\mathrm{a}}$ & $29.470 \pm 2.408^{\mathrm{a}}$ & $31.114 \pm 1.324^{\mathrm{a}, \mathrm{b}}$ \\
Testis weight $(\mathrm{g})$ & $0.099 \pm 0.012$ & $0.100 \pm 0.003$ & $0.014 \pm 0.002^{\mathrm{a}}$ & $0.035 \pm 0.002^{\mathrm{a}, \mathrm{b}}$ & $0.100 \pm 0.006^{\mathrm{b}}$ \\
Epididymal spermatozoa $\left(\times 10^{5}\right)$ & $20.493 \pm 2.362$ & $26.968 \pm 1.527^{\mathrm{a}}$ & $0.272 \pm 0.011^{\mathrm{a}}$ & $6.673 \pm 0.510^{\mathrm{a}, \mathrm{b}}$ & $20.893 \pm 1.677^{\mathrm{b}}$ \\
Fertility rate & $100 \%(10 / 10)$ & $100 \%(10 / 10)$ & $0 \%(0 / 10)^{\mathrm{a}}$ & $20 \%(2 / 10)^{\mathrm{a}, \mathrm{b}}$ & $100 \%(10 / 10)^{\mathrm{b}}$ \\
\hline
\end{tabular}

Data are presented as mean \pm standard deviation. ${ }^{a} p<0.05$ vs. group I; ${ }^{b} p<0.05$ vs. group III.

In groups I and II (no BSF treatment), histological examination of the testes demonstrated intact seminiferous tubules with normal spermatogenesis from spermatogonia to spermatozoa in the cycle of germinal epithelium (Figure 1A(I,II)). BSF treatment induced the appearance of atrophic seminiferous tubules and azoospermia in group III mice (Figure 1A(III)). A partial recovery of spermatogenesis was observed in group IV mice that received a TJ107 diet from day 0. Furthermore, in these mice, seminiferous tubules that exhibited intact spermatogenesis were found adjacent to the seminiferous tubules that showed aspermatogenesis as Sertoli cells only (Figure 1A(IV)). In contrast, in group V, the administration TJ107 from day 60 restored normal spermatogenesis in all the seminiferous tubules (Figure $1 \mathrm{~A}(\mathrm{~V}))$.

Furthermore, we compared the expression levels of mRNA species encoding premeiotic cells (cKit, Gfra1, and Vasa), meiotic and postmeiotic cells (Boll, Crem, Prm1, and Acrosin) (Figure 1C), the spermatogonial marker Stra8, the spermatocyte marker of Spo11, and the spermatid marker Tnp1 (Figure 1B) [15-23] by real-time RT-PCR analysis in each group at day 120. The levels of all examined ten spermatogenesis markers were significantly reduced in group III but completely recovered in group V; the expression recovered slightly in group IV but remained significantly less than that in group $\mathrm{V}$ and normal mice. 
A
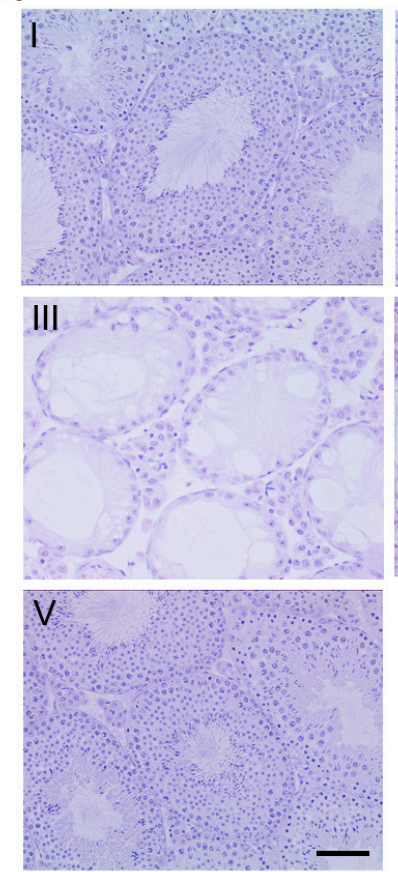

\section{$\mathrm{C}_{\text {Pre-meiotic markers }}$}

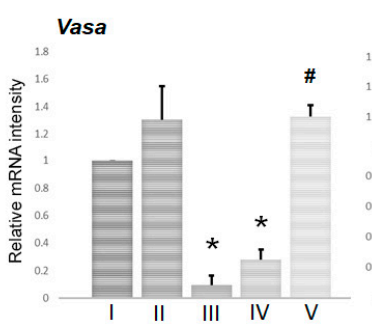

Gfra1

IV

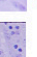

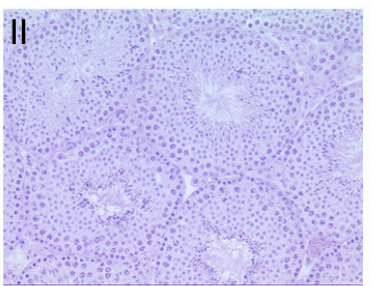
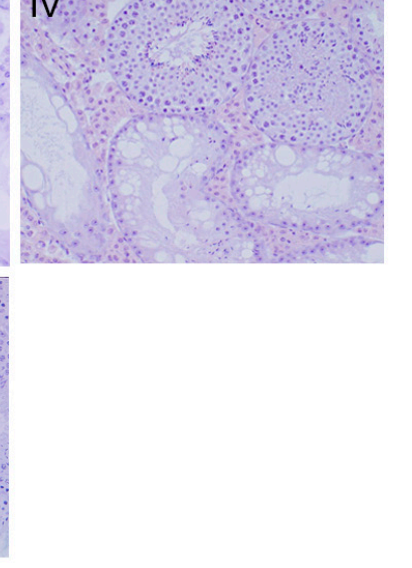

B ${ }_{25}$ Stra8
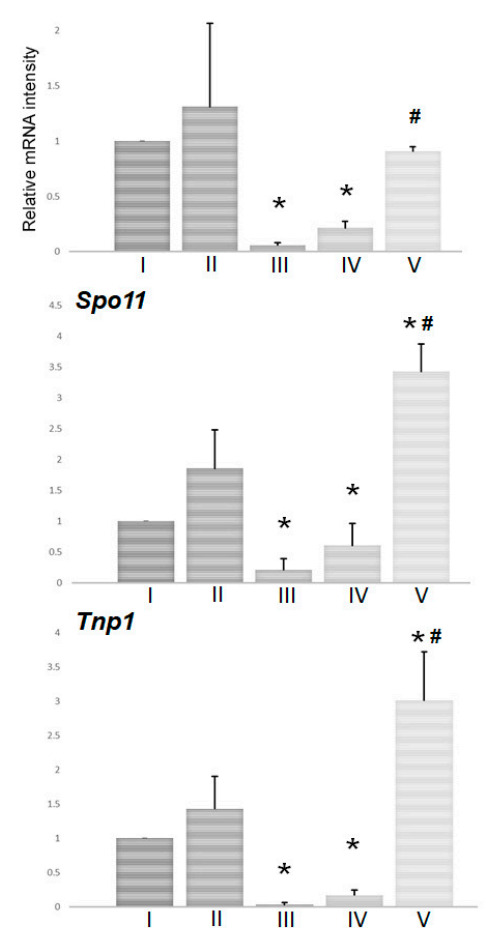
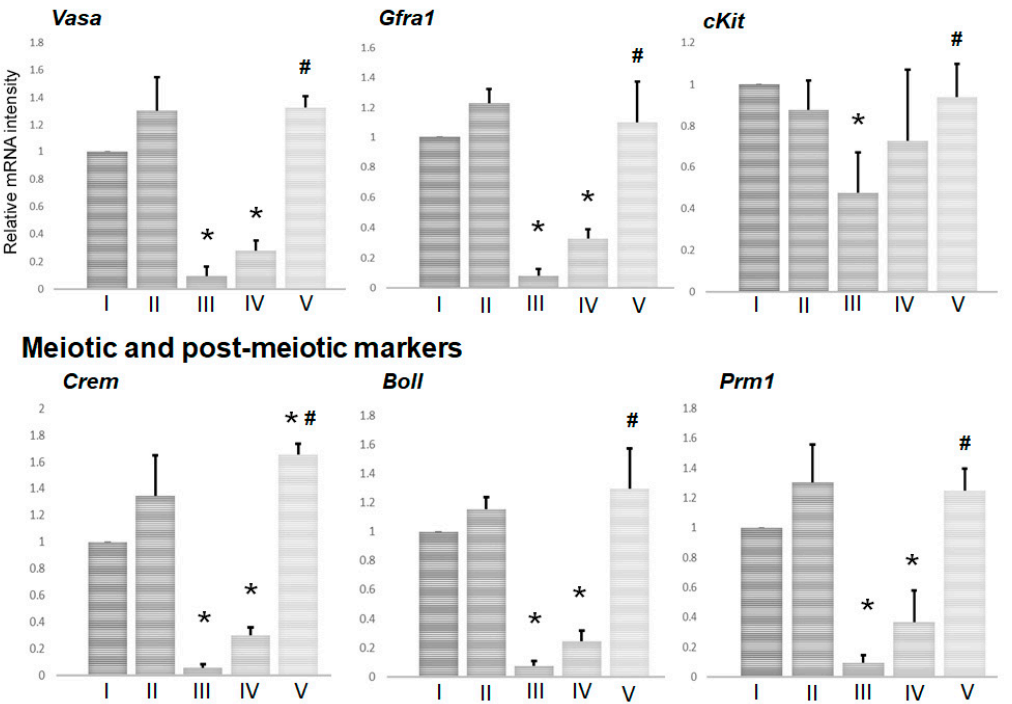

kers Boll

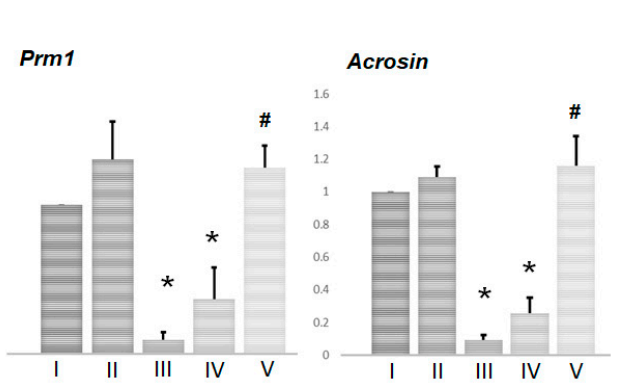

Figure 1. Testicular histology and the levels of three mRNA transcripts encoding markers of germ cell differentiation in each group at day $120(n=5)$ : (A) testes sections show morphology in groups I-V. Intact seminiferous tubules showing normal germinal epithelium from the spermatogonia to spermatozoa are observed in groups I and II. Atrophic seminiferous tubules with azoospermia are observed in group III. The presence of both atrophic and intact seminiferous tubules with spermatogenesis was observed in the group IV mice. Normal-appearing seminiferous tubules are observed in the group V mice (bar $=50 \mu \mathrm{m})$. (B) Expression was measured by real-time RT PCR, and the results are expressed relative to the internal control GAPDH. Data show expression of the spermatogonial marker Stra8, the spermatocyte marker Spo11, and the spermatid marker Tnp1. The results are expressed as the mean values \pm standard deviation of five mice in each group, and the $y$-axis shows relative mRNA intensity. (C) Expression was measured by real-time RT PCR, and the results are expressed relative to the internal control GAPDH. Data show expression of the premeiotic markers (cKit, Gfra1, and Vasa), and the meiotic and postmeiotic markers (Boll, Crem, Prm1, and Acrosin). The results are expressed as the mean values \pm standard deviation of five mice in each group, and the $y$-axis shows relative mRNA intensity. ${ }^{*} p<0.05$ vs. group I; ${ }^{\#} p<0.05$ vs. group III. 


\subsection{Effect of TJ107 on Levels of mRNA Transcripts Encoding Markers of Sertoli Cell-Specific Products at Day 120}

To examine the effects of TJ107 on Sertoli cell function regulated by BSF-induced germ cell depletion, the levels of 25 Sertoli cell-specific mRNA species were measured in each group at day 120 (Figure 2). Five mRNA species (Amh, Clu, Shbg, Testin, and Illa) showed significantly increased expression (Figure 2A) in response to BSF, and five mRNA species (Aqp8, CST9, Fshr, Wnt5a, and Tjp1) showed decreased expression (Figure 2B). Of these, Amh and Fshr showed a degree of recovered expression in group IV, while all ten mRNA species showed completely recovered expression in group $\mathrm{V}$ (Figure 2A,B). There were no significant changes in the expression levels of the remaining $15 \mathrm{mRNA}$ species (Ccnd2, Cst12, Dhh, Espn, Fyn, GATA1, Inhba, Inhbb, Cldn11, Msi1, Rhox5, Spata2, Sox9, Trf, and Wt1) after BSF treatment in group III, although Fyn and Trf were markedly increased by TJ107 administration in groups II, IV, and V (Figure 2C).

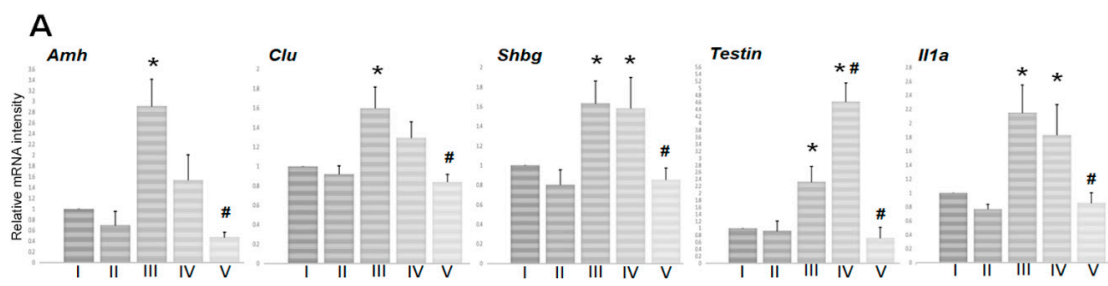

B

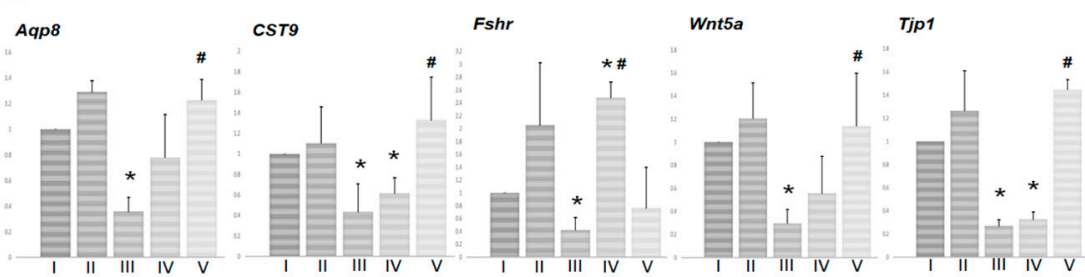

C cST12
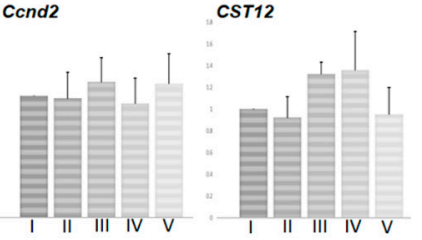

Dhh

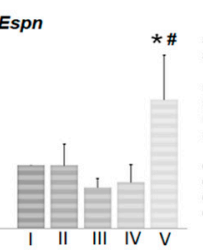

GATA1

Fyn

Inhba

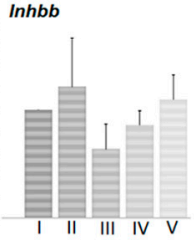

Cldn11

Sox
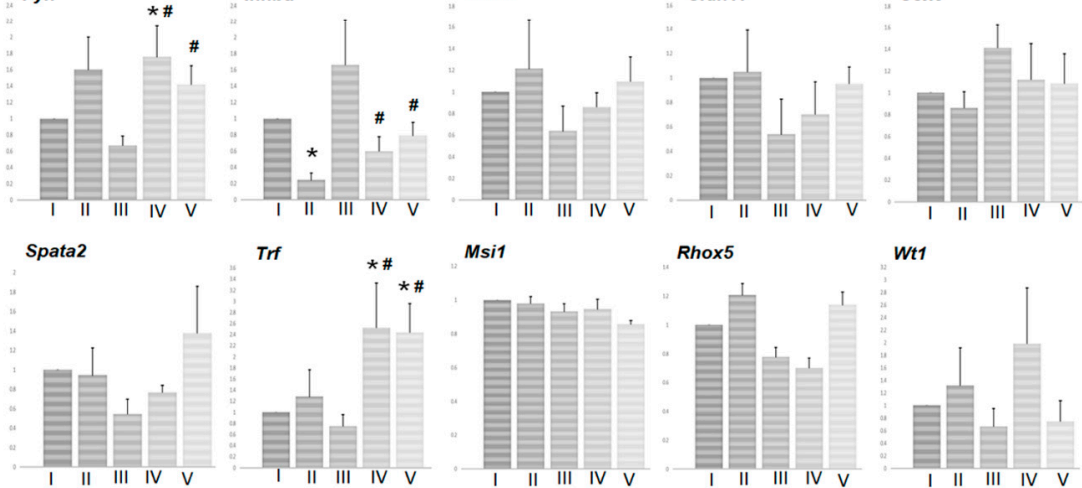

Msi1

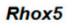

Wt1
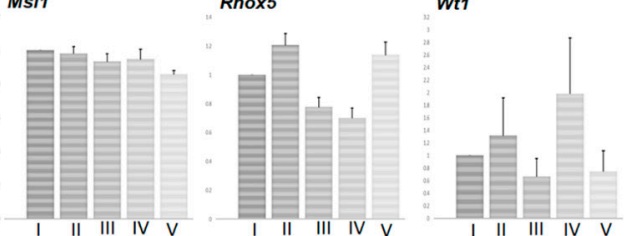

Figure 2. Effect of TL107 on the levels of 25 mRNA transcripts encoding markers of Sertoli cell-specific products in each group at day 120: expression was measured by real-time RT PCR, and the results are expressed relative to the internal control GAPDH. The results are expressed as the mean values \pm standard deviation of five mice in each group, and the y-axis shows relative mRNA intensity. Transcripts showing a significant increase in levels after BSF treatment compared to control values are grouped in (A); transcripts showing a significant decrease in levels after BSF treatment compared to control values are grouped in (B). Transcripts that showed no change in levels after BSF treatment are grouped in (C). ${ }^{*} p<0.05$ vs. group I; ${ }^{\#} p<0.05$ vs. group III. 


\subsection{Effects of Supplemented TJ107 from Day 0 on Spermatogenesis in Group IV at Day 60}

We performed histological analysis and analysis of the specific mRNA species in the testes of group III and IV mice at day 60 in order to clarify the mechanism of the different therapeutic effects of TJ107 at different administration times on BSF-induced aspermatogenesis. The body weight of the mice in groups III and IV were not significantly different to group I mice (treated with DMSO) at day 60 (Figure 3D). In group IV mice, the epididymal spermatozoa counts, but not the testicular weights, were significantly increased compared to group III mice but still significantly lower compared to group I mice (Figure 3D). In the histological examination of the testes, spermatogenesis from spermatogonia to spermatozoa in the cycle of germinal epithelium were observed in the seminiferous tubules of normal group I mice (Figure 3A(I)). In contrast, in the BSF-treated mice without (group III) or with (group IV) a TJ107 diet, both atrophic seminiferous tubules and intact seminiferous tubules with spermatogenesis was observed (Figure 3A(III,IV)). In the measurement of mRNA levels, spermatogenesis markers encoding pre-meiotic cells (cKit, Gfra1, and Vasa), meiotic and postmeiotic cells (Boll, Crem, Prm1, and Acrosin), the spermatogonial marker Stra8, the spermatocyte marker of Spo11, and the spermatid marker Tnp1 were significantly decreased in groups III and IV compared to group I. Furthermore, the expressions of all ten mRNAs were not significantly different between groups III and IV (Figure 3B,C).
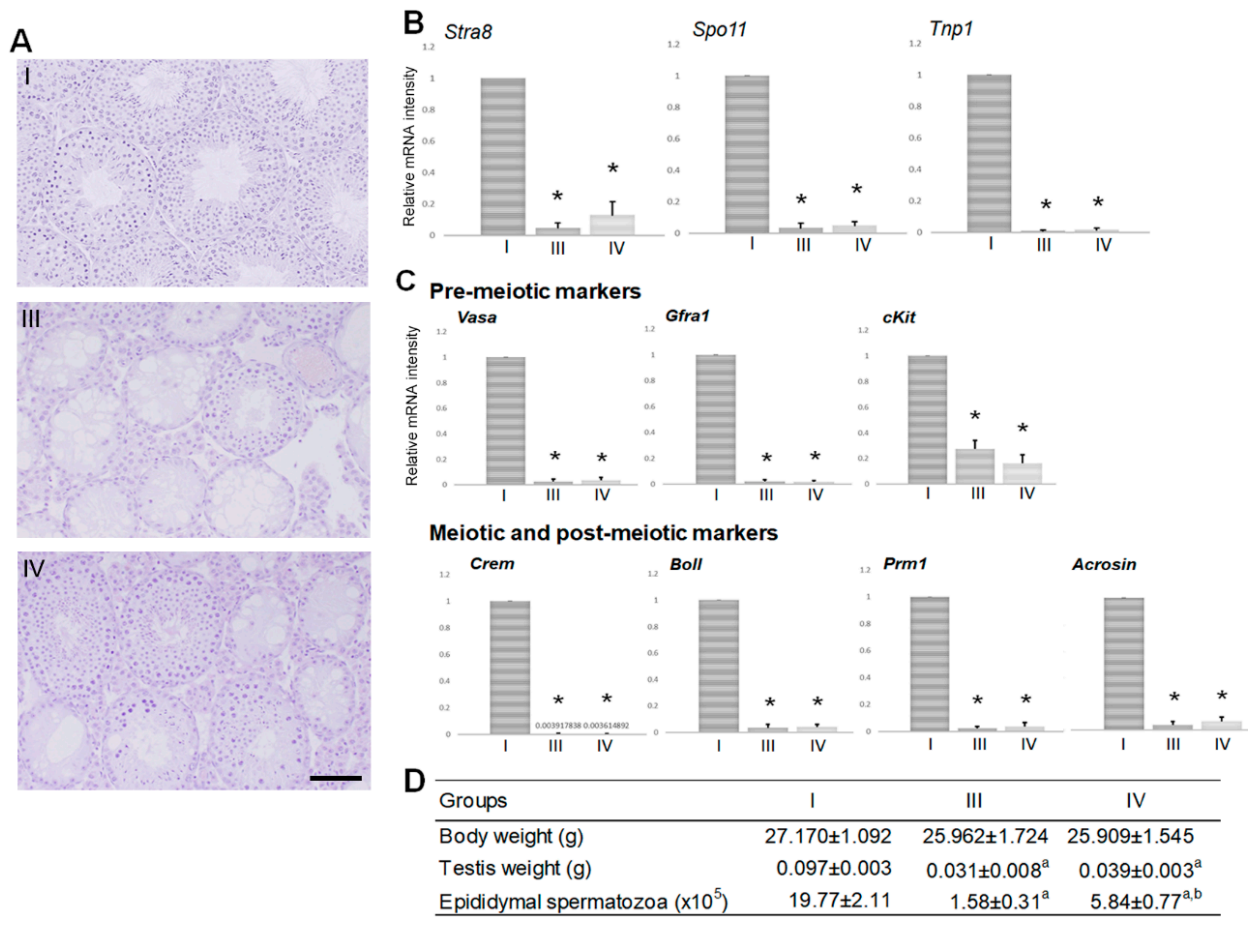

Figure 3. Testicular histology and levels of three mRNA transcripts encoding markers of germ cell differentiation in groups I, III, and IV at day $60(n=5)$ : (A) seminiferous tubules showing normal spermatogenesis from spermatogonia to spermatozoa are observed in the group I mice. Both atrophic and intact seminiferous tubules with spermatogenesis were observed in the group III and group IV mice (bar $=40 \mu \mathrm{m})$. (B,C) Expression was measured by real-time RT PCR, and the results are expressed relative to the internal control GAPDH. (B) Data show expression of the spermatogonial marker Stra8, the spermatocyte marker Spo11, and the spermatid marker Tnp1. (C) Data show expression of the premeiotic markers (cKit, Gfra1, and Vasa), and the meiotic and postmeiotic markers (Boll, Crem, Prm1, and Acrosin). The results are expressed as the mean values \pm standard deviation of five mice in each group, and the y-axis shows relative mRNA intensity. ${ }^{*} p<0.05$ vs. group I. (D) Testicular weights and epididymal spermatozoa count in groups I, III, and IV. Data are presented as mean \pm standard deviation. ${ }^{\mathrm{a}} p<0.05$ vs. group I; ${ }^{\mathrm{b}} p<0.05$ vs. group III. 
Upon examining the effects of TJ107 on Sertoli cell function after BSF treatment, the same Sertoli cell-specific mRNA species levels were measured in groups III and IV at day 60 (Figure 4). In response to BSF at day 60, the levels of five mRNA species (Amh, Clu, Shbg, Testin, and Il1a) were significantly increased (Figure 4A), while the levels of six mRNA species (Aqp8, CST9, Espn, Wnt5a, Tjp1, and Trf) were significantly decreased (Figure 4B); among these, there were no significant differences between groups III and IV. There were no significant differences in the expression levels of the remaining 14 mRNA species (Ccnd2, Cst12, Dhh, Fshr, Fyn, GATA1, Inhba, Inhbb, Cldn11, Msi1, Rhox5, Spata2, Sox9, and Wt1) following BSF treatment in group III. However, Fshr and Cldn11 were decreased and Inhba was increased in group IV mice following administration of TJ107 (Figure 4C).
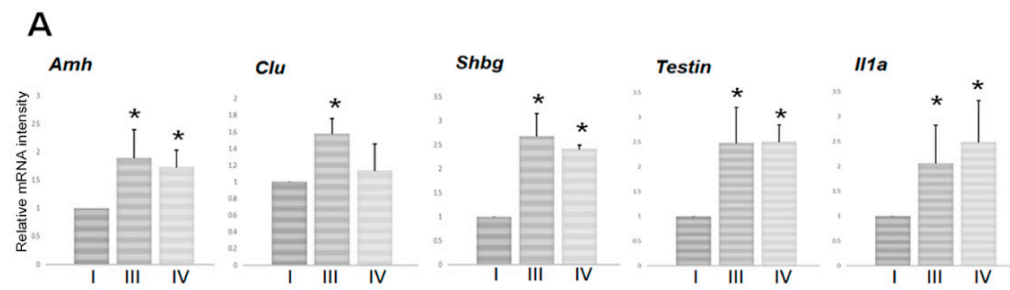

B

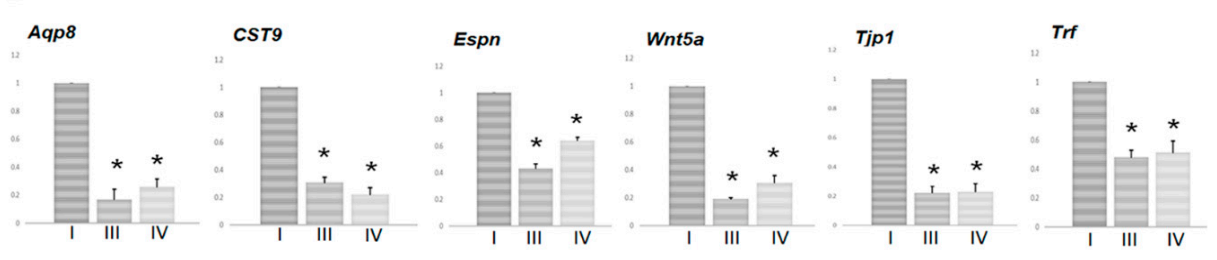

C
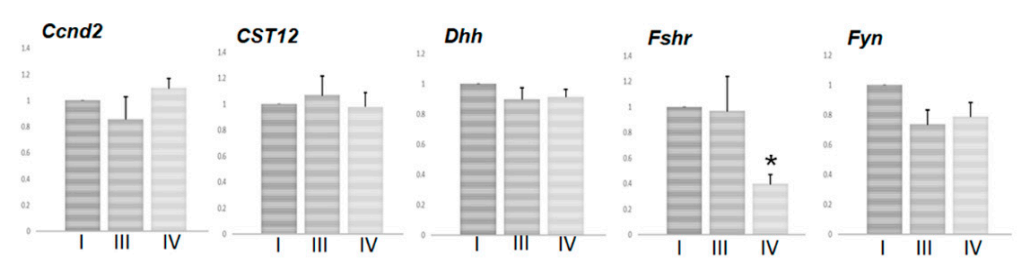

GATA1

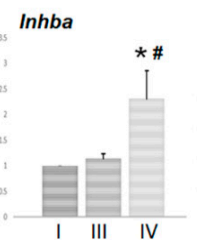

Inhbb
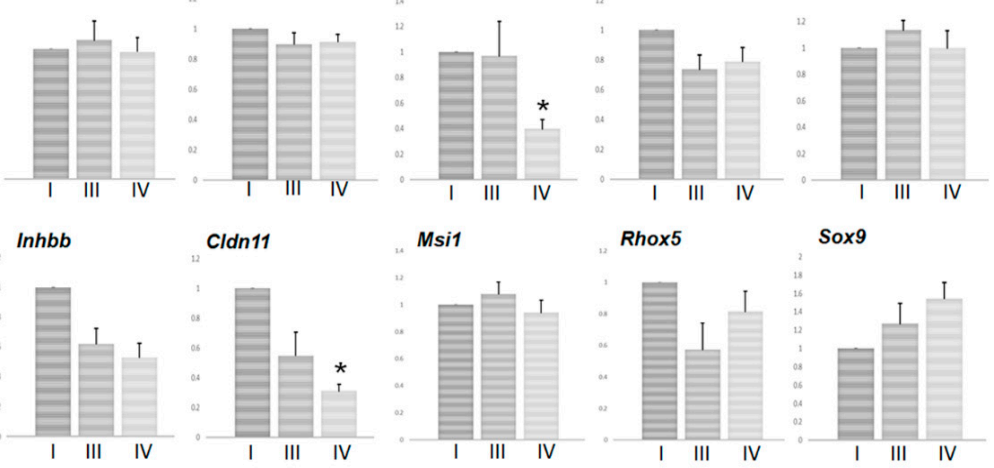

Sox9

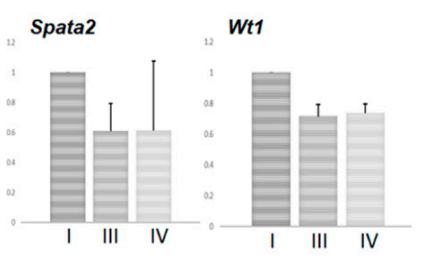

Figure 4. Effect of TL107 on the expression levels of 25 mRNA transcripts encoding markers of Sertoli cell-specific products in groups I, III, and IV mice at day 60: expression was measured by real-time RT $\mathrm{PCR}$, and the results are expressed relative to the internal control GAPDH. The results are expressed as the mean values \pm standard deviation of five mice in each group, and the $y$-axis shows relative mRNA intensity. Transcripts showing a significant increase in levels after BSF treatment compared to control values are grouped in (A); transcripts showing a significant decreased in levels after BSF treatment compared to control values are grouped in (B); and transcripts showing no change in levels after BSF treatment are grouped in $(\mathbf{C}) .{ }^{*} p<0.05$ vs. group I; ${ }^{*} p<0.05$ vs. group III. 


\section{Discussion}

In this study, we examined the different effects of TJ107 on BSF-induced aspermatogenesis for 120 days in response to different times of administration after BSF injection. Our results demonstrated that only supplemented TJ107 at day 60 after BSF injection could significantly recover spermatogenesis with the development of the meiotic and postmeiotic stages from spermaotgonial cells at day 120 . On further examination of the 25 markers of Sertoli cell-specific products, we demonstrated that only supplementation of TJ107 at day 60 after BSF injection could significantly recover the increase in five mRNA species (Amh, Clu,Shbg, Testin, and Il1a) and the decrease in four mRNA species (Aqp8, CST9, Wnt5a, and Tjp1) in response to BSF at day 120, with the increase of germ cell differentiation. To the best of our knowledge, this is the first study to demonstrate the effects of the oriental medicine TJ107 on Sertoli cells in the context of spermatogenesis. Furthermore, the abovementioned mRNA species showed the same changes in response to BSF at day 60; therefore, it is likely that these nine mRNA transcripts encoding Sertoli cell-specific products are associated with male infertility after BSF chemotherapy.

We have previously demonstrated that TJ107 or administration of Hachimi-jio-gan (TJ7) and Hochu-ekki-to (TJ41) in combination were able to completely normalize testicular immunopathology and to promote recovery from severe aspermatogenesis after BSF treatment in mice [9,14]. We further showed that BSF treatment upregulated the expression of TNF- $\alpha, M C P-1, T L R 2$, and TLR4 in the testes, which was completely reversed by TJ107, or TJ7 and TJ41 coadministration $[9,14]$. This study is the first to examine whether TJ107 could recover spermatogenesis after 120 days by administering from the day of BSF injection. It has been previously demonstrated that treatment with BSF has no effect on the intratesticular levels of testosterone, which confirms the findings that germ cell ablation has no significant effect on testosterone levels [24,25]. Furthermore, O'Shaughnessy demonstrated that the levels of mRNA transcripts encoding Leydig cell-specific products related to steroidogenesis were unaffected by BSF treatment [23]. In the current study, we further examined the markers of Sertoli cell-specific products and germ cell differentiation in order to clarify the mechanism of the different therapeutic effects of TJ107 observed at different times of administration on BSF-induced infertility.

The mice treated with BSF showed a significant decrease in body weight, testes weight, and epididymal spermatozoa counts at day 60 (Figure 3A(III)), which was more pronounced at day 120 (Figure 1A(III)) in agreement with our previous studies [9,14]. Furthermore, supplementation with TJ107 could lead to significant improvement in body weight but not complete recovery in groups IV and V (Table 2). In contrast, complete recovery of testes weight, the development of spermatogonial cells to meiotic and postmeiotic stages including the generation of testicular spermatozoa, epididymal spermatozoa counts, and fertility rate was only observed in mice that subsequently received TJ107 at day 60 after BSF treatment in group V (Table 2; Figure 1A(V),B), while a modicum of improvements was detected in that of group IV (Table 2; Figure 1A(IV),B). Furthermore, the difference in the offspring number between group IV $(0.20 \pm 0.09)$ and $V(3.27 \pm 2.01)$ is also detected. These results indicated that only administration of TJ107 at day 60 after BSF treatment might able to completely regenerate the seminiferous epithelium that was injured by treatment with BSF.

We next examined the effects of TJ107 on Sertoli cell function after BSF treatment at day 60 and day 120 in order to clarify the mechanism of the different therapeutic effects. BSF treatment led to an increase in five mRNA species (Amh, Clu, Shbg, Testin, and Il1a) from day 60 to day 120, which were only recovered by supplementation with TJ107 in group V at day 120 (Figure 2A) but not in group IV at both day 60 (Figure 4A) and day 120 (Figure 2A). Furthermore, BSF treatment led to a decrease in mRNA species at day 60 (Aqp8, CST9, Espn, Wnt5a, Tjp1, and Trf) and day 120 (Aqp8, CST9, Fshr, Wnt5a, and Tjp1), and four mRNA species (Aqp8, CST9, Wnt5a and Tjp1) were recovered by supplementation with TJ107 in group V at day 120 (Figure 2B). The mRNAs that were decreased showed no recovery in group IV at day 60 (Figure 4B) and at day 120, with the exception of Fshr, which was significantly increased (Figure 2B). Furthermore, administration of TJ107 affected the expression of Inhba and Cldn11 at day 60 (Figure 4C) and Fyn and Inhba at day 120 (Figure 2C), although these mRNA species showed 
no changes after BSF treatment. The mRNA species that were stably expressed in response to BSF (increased in five mRNA species: Amh, Clu, Shbg, Testin, and Il1a; decreased in four mRNA species: Aqp8, Cst9, Wnt5a, and Tjp1) showed restored expression and completely recovered spermatogenesis in group $\mathrm{V}$ mice.

Spermatogenesis is a complex and tightly regulated process that leads to continuous production of male gametes, the spermatozoa. The maintenance of spermatogonial stem cells provides the foundation for life-long spermatogenesis. In mice, Wnt5a is male-specifically upregulated within testicular interstitial cells at the onset of gonad differentiation and has been shown to be a cell-extrinsic factor that supports self-renewal of spermatogonial stem cells [26]. In the present study, the Wnt5a mRNA species decreased in response to BSF, with severe aspermatogenesis that was recovered by supplementation with TJ107 in group V mice. Sertoli cells are somatic cells of the testis that support the architectural stability of germ cells and conserve the microenvironment and blood-testis barrier. Moreover, Sertoli cells produce various hormones that play essential roles in gonadal development and the survival of spermatogonial cells. Anti-Müllerian hormone $(A m h)$ is one such hormone expressed in Sertoli cells of the fetal and adult testes [27,28]. Furthermore, sex hormone-binding globulin (Shbg) is produced and secreted by the liver into the bloodstream, where it binds sex steroids and regulates their bioavailability. In rodents, the Shbg gene is also expressed in Sertoli cells and has been shown to significantly affect total-androgen levels [29]. In our study, the rise in Amh and Shbg following treatment with BSF may be consistent with regulation by the loss of germ cells. Throughout spermatogenesis, the Sertoli cell blood-testis barrier is an important structural component consisting of tight junction proteins such as occludin, Cldn11, and tight junction protein 1 (Tjp1) [30]. Furthermore, the Sertoli cell blood-testis barrier is strictly regulated by cytokines such as interleukin-1 $\alpha(I l 1 \alpha)$, and germ cells are known to control production of this cytokine by Sertoli cells [31]. Although we did not detect BSF-induced impairment of the blood-testis barrier [32], the decreased expression of Tjp1 and the increased expression of $I l 1 \alpha$ warrant further investigation.

It is well known that Testin is a testosteron-responsive Sertoli cell secretory product. Testin is localized on the surface of Sertoli cells which allows contact with germ cells [33,34]; consequently, depletion of germ cells leads to an increase of Testin mRNA [34], which is consistent with the results of the present study. Some studies have demonstrated that clusterin (Clu) is secreted by the Sertoli cells in rats [35] and deposited onto the membranes of elongating spermatids and mature spermatozoa [36]. Recently, Fukuda et al. reported the use of the seminal Clu level as a biomarker for assessment of spermatogenic status in infertile men [37]. In the present study, we first demonstrated that Clu mRNA was increased in response to germ cell depletion by BSF treatment and was restored with completely recovered spermatogenesis.

Previous studies have shown various molecular mechanisms by which BSF mediates toxic effects on spermatogenesis [5,38]; these include targeting genes expressed in the testis. It is well known that Sertoli cells support and organize the stability of spermatogenesis and conserve the testicular microenvironment. In line with this, O'Shaughnessy et al. demonstrated that the transcript levels of nine mRNAs were increased (Amh, Clu, Cldn11, Cst9, Cys12, Il1a, Shbg, Testin, and Wnt5a) and two were decreased (Spata2 and Sympk) in response to BSF treatment [23]. Furthermore, there were no changes in the expression levels of 16 Sertoli cell genes (Ccnd2, Cldn11, Cst12, Dhh, Espn, Fshr, Fyn, GATA1, Inhba, Inhbb, Msi1, Rhox5, Spata2, Sox9, Trf, and Wt1) in our present study. Among these Sertoli cell genes, 11 mRNAs (Ccnd2, Dhh, Espn, Fshr, Fyn, GATA1, Inhba, Msi1, Rhox5, Sox9, and Wt1) were reported by O'Shaughnessy et al. [23] and the different expressions were seen in $5 \mathrm{mRNAs}$ (Cldn11, Cst12, Inhbb, Spata2, and Trf). The different dose of BSF (30 mg/kg), different age of recipient mice (15 weeks), and different experimental period (50 days after BSF injection) are causally related to the differences observed between the two studies. Furthermore, Sertoli cell activity is particularly sensitive to regulation by meiotic germ cells [39-41], and we demonstrate altered Sertoli cell function after BSF treatment at day 120, with intact spermatogenesis showing Sertoli cells only in the seminiferous tubules. Therefore, Sertoli cell factors may be intimately interrelated with spermatogenesis after BSF 
chemotherapy and may assist with providing an estimation of male fertility. Although the mechanism by which TJ107 led to improvement only 60 days after injection of BSF but not from the beginning for 120 days is not clear yet, we will sort out Sertoli cells before RNA isolation step and immune-stain testes sections with antibodies recognizing the analyzed markers to experimentally prove the fact of Sertoli cell-specific changes in gene expression upon BSF or BSF + TJ107 treatments in our next study. For possible future therapeutic strategies to male infertility treatment, mainly after chemotherapy, we will also examine the presence of germ cells by immunofluorescence-staining of each spermatogenic stage upon BSF or BSF + TJ107 treatments.

Author Contributions: Experiments were designed by N.Q., K.S. (Kou Sakabe) and M.I.; K.N., N.Q. and M.K. performed the experiments. Histological and histopathological analyses of the testes and epididymis were performed by M.K., K.N. and N.Q. Statistical analyses were performed by S.H., Y.O. and N.Q. drafted the original manuscript and discussed the manuscript with M.I. Secretarial and technical assistance were performed by K.S. (Kaori Suyama) and K.S. (Kou Sakabe). All authors have read and agreed to the published version of the manuscript.

Funding: This work was supported by the Grant-in-Aid for General Science Research (C: $15 \mathrm{~K} 08937$ and C: 19K07876) from the Ministry of Education Science Sports and Culture in Japan and by the 2018 Tokai University School of Medicine Research Aid.

Acknowledgments: Gosha-jinki-gan extracts were manufactured by Tsumura \& Co. (Tokyo, Japan). The authors wish to acknowledge the Support Center for Medical Research and Education, Tokai University.

Conflicts of Interest: The authors declare no conflict of interest. The funders had no role in the design of the study; in the collection, analyses, or interpretation of data; in the writing of the manuscript; or in the decision to publish the results.

\section{References}

1. Buggia, I.; Locatelli, F.; Regazzi, M.B.; Zecca, M. Busulfan. Ann. Pharm. 1994, 28, 1055-1062. [CrossRef]

2. Galaup, A.; Paci, A. Pharmacology of dimethanesulfonate alkylating agents: Busulfan and treosulfan. Expert Opin. Drug Metab. Toxicol. 2013, 9, 333-347. [CrossRef]

3. Anand, S.; Bhartiya, D.; Sriraman, K.; Mallick, A. Underlying mechanisms that restore spermatogenesis on transplanting healthy niche cells in busulphan treated mouse testis. Stem Cell Rev. Rep. 2016, 12, 682-697. [CrossRef]

4. Bhartiya, D.; Anand, S. Effects of oncotherapy on testicular stem cells and niche. Mol. Hum. Reprod. 2017, 23, 654-655. [CrossRef] [PubMed]

5. Choi, Y.J.; Ok, D.W.; Kwon, D.N.; Chung, J.I.; Kim, H.C.; Yeo, S.M.; Kim, T.; Seo, H.G.; Kim, J.H. Murine male germ cell apoptosis induced by busulfan treatment correlates with loss of c-kit-expression in a Fas/FasL- and p53-independent manner. FEBS Lett. 2004, 575, 41-51. [CrossRef] [PubMed]

6. Li, B.; He, X.; Zhuang, M.; Niu, B.; Wu, C.; Mu, H.; Tang, F.; Cui, Y.; Liu, W.; Zhao, B.; et al. Melatonin ameliorates busulfan-induced spermatogonial stem cell oxidative apoptosis in mouse testes. Antioxid. Redox Signal. 2018, 28, 385-400. [CrossRef] [PubMed]

7. Xian, Y.; Wu, M.; Liu, Y.; Hao, J.; Wu, Y.; Liao, X.; Li, G. Increased Sat2 expression is associated with busulfan-induced testicular Sertoli cell injury. Toxicol. Vitr. 2017, 43, 47-57. [CrossRef]

8. Zhang, X.; Wang, T.; Deng, T.; Xiong, W.; Lui, P.; Li, N.; Chen, Y.; Han, D. Damaged spermatogenic cells induce inflammatory gene expression in mouse Sertoli cells through the activation of Toll-like receptors 2 and 4. Mol. Cell. Endocrinol. 2013, 365, 162-173. [CrossRef]

9. Qu, N.; Kuramasu, M.; Hirayanagi, Y.; Nagahori, K.; Hayashi, S.; Ogawa, Y.; Terayama, H.; Suyama, K.; Naito, M.; Sakabe, K.; et al. Gosha-Jinki-Gan recovers spermatogenesis in mice with busulfan-induced aspermatogenesis. Int. J. Mol. Sci. 2018, 19, 2606. [CrossRef]

10. Galton, D.A.; Till, M.; Wiltshaw, E. Busulfan (1,4-dimethanesulfonyloxybutane, Myleran): Summary of clinical results. Ann. N. Y. Acad. Sci. 1958, 68, 967-973. [CrossRef]

11. Kenis, Y.; Dustin, P.; Henry, J.A.; Tagnon, H.J. Action du Myleran dans 22 cas de leucemie myeloide chromique. Rev. Fr. Etudes Clin. Biol. 1956, 1, 435-442.

12. Kyle, R.A.; Schwartz, R.S.; Oliner, H.L.; Dameshek, W. A syndrome resembling adrenal cortical insufficiency associated with long-term busulfan (Myleran) therapy. Blood 1961, 18, 497-510. [CrossRef] [PubMed] 
13. Hirayanagi, Y.; Qu, N.; Hirai, S.; Naito, M.; Terayama, H.; Hayashi, S.; Hatayama, N.; Kuramasu, M.; Ogawa, Y.; Itoh, M. Busulfan pretreatment for transplantation of rat spermatogonia differentially affects immune and reproductive systems in male recipient mice. Anat. Sci. Int. 2015, 90, 264-274. [CrossRef] [PubMed]

14. Qu, N.; Kuramasu, M.; Nagahori, K.; Ogawa, Y.; Hayashi, S.; Hirayanagi, Y.; Terayama, H.; Suyama, K.; Sakabe, K.; Itoh, M. Co-administration of the traditional medicines Hachimi-Jio-Gan and hochu-ekki-to can reverse busulfan-induced aspermatogenesis. Int. J. Mol. Sci. 2020, 21, 1716. [CrossRef] [PubMed]

15. Niedenberger, B.A.; Busada, J.T.; Geyer, C.B. Marker expression reveals heterogeneity of spermatogonia in the neonatal mouse testis. Reproduction. 2015, 149, 329-338. [CrossRef]

16. AbuMadighem, A.; Solomon, R.; Stepanovsky, A.; Kapelushnik, J.; Shi, Q.; Meese, E.; Lunenfeld, E.; Huleihel, M. Development of spermatogenesis in vitro in three-dimensional culture from spermatogonial cells of busulfan-treated immature mice. Int. J. Mol. Sci. 2018, 19, 3804. [CrossRef]

17. Abofoul-Azab, M.; Lunenfeld, E.; Levitas, E.; Zeadna, A.; Younis, J.S.; Bar-Ami, S.; Huleihe, M. Identification of Premeiotic, Meiotic, and Postmeiotic Cells in Testicular Biopsies Without Sperm from Sertoli Cell-Only Syndrome Patients. Int. J. Mol. Sci. 2019, 20, 470. [CrossRef]

18. O'Shaughnessy, P.J.; Abel, M.; Charlton, H.M.; Hu, B.; Johnston, H.; Baker, P.J. Altered expression of genes involved in regulation of vitamin a metabolism, solute transportation, and cytoskeletal function in the androgen-insensitive tfm mouse testis. Endocrinology 2007, 148, 2914-2924. [CrossRef]

19. O'Shaughnessy, P.J.; Baker, P.J.; Monteiro, A.; Cassie, S.; Bhattacharya, S.; Fowler, P.A. Developmental changes in human fetal testicular cell numbers and messenger ribonucleic acid levels during the second trimester. J. Clin. Endocrinol. Metab. 2007, 92, 4792-4801.

20. Yelick, P.C.; Kwon, Y.H.; Flynn, J.F.; Borzorgzadeh, A.; Kleene, K.C.; Hecht, N.B. Mouse transition protein 1 is translationally regulated during the postmeiotic stages of spermatogenesis. Mol. Reprod Dev. 1989, 1, 193-200. [CrossRef]

21. Oulad-Abdelghani, M.; Bouillet, P.; Décimo, D.; Gansmuller, A.; Heyberger, S.; Dollé, P.; Bronner, S.; Lutz, Y.; Chambon, P. Characterization of a premeiotic germ cell-specific cytoplasmic protein encoded by Stra8, a novel retinoic acid-responsive gene. J. Cell Biol. 1996, 135, 469-477. [CrossRef] [PubMed]

22. Shannon, M.; Richardson, L.; Christian, A.; Handel, M.A.; Thelen, M.P. Differential gene expression of mammalian SPO11/TOP6A homologs during meiosis. FEBS Lett. 1999, 462, 329-334. [CrossRef]

23. O'Shaughnessy, P.J.; Hu, L.; Baker, P.J. Effect of germ cell depletion on levels of specific mRNA transcripts in mouse Sertoli cells and Leydig cells. Reproduction 2008, 135, 839-850. [CrossRef] [PubMed]

24. Morris, I.D.; Bardin, C.W.; Musto, N.A.; Thau, R.B.; Gunsalus, G.L. Evidence suggesting that germ cells influence the bidirectional secretion of androgen binding protein by the seminiferous epithelium demonstrated by selective impairment of spermatogenesis with busulphan. Int. J. Androl. 1987, 10, 691-700. [CrossRef] [PubMed]

25. De Franca, L.R.; Bartke, A.; Borg, K.E.; Cecim, M.; Fadden, C.T.; Yagi, A.; Russell, L.D. Sertoli cells in testes containing or lacking germ cells: A comparative study of paracrine effects using the $\mathrm{W}$ (c-kit) gene mutant mouse model. Anat. Rec. 1994, 240, 225-232. [CrossRef]

26. Yeh, J.R.; Zhang, X.; Nagano, M.C. Wnt5a is a cell-extrinsic factor that supports self-renewal of mouse spermatogonial stem cells. J. Cell Sci. 2011, 124, 2357-2366. [CrossRef]

27. Teixeira, J.; Maheswaran, S.; Donahoe, P.K. Mullerian inhibiting substance: An instructive developmental hormone with diagnostic and possible therapeutic applications. Endocr. Rev. 2001, 22, 657-674. [CrossRef]

28. Cimino, I.; Casoni, F.; Liu, X.; Messina, A.; Parkash, J.; Jamin, S.P.; Catteau-Jonard, S.; Collier, F.; Baroncini, M.; Dewailly, D.; et al. Novel role for anti-Mullerian hormone in the regulation of GnRH neuron excitability and hormone secretion. Nat. Commun. 2016, 7, 10055. [CrossRef]

29. Selva, D.M.; Hogeveen, K.N.; Hammond, G.L. Repression of the human sex hormone-binding globulin gene in Sertoli cells by upstream stimulatory transcription factors. J. Biol. Chem. 2005, 280, 4462-4468. [CrossRef] [PubMed]

30. Pérez, C.V.; Sobarzo, C.M.; Jacobo, P.V.; Pellizzari, E.H.; Cigorraga, S.B.; Denduchis, B.; Lustig, L. Loss of occludin expression and impairment of blood-testis barrier permeability in rats with autoimmune orchitis: Effect of interleukin 6 on sertoli cell tight junctions. Biol. Reprod. 2012, 87. [CrossRef]

31. Lie, P.P.Y.; Cheng, C.Y.; Mruk, D.D. Interleukin-1alpha is a regulator of the blood-testis barrier. FASEB J. 2011, 25, 1244-1253. [CrossRef] [PubMed] 
32. Qu, N.; Itoh, M.; Sakabe, K. Effects of chemotherapy and radiotherapy on spermatogenesis: The role of testicular immunology. Int. J. Mol. Sci. 2019, 20, 957. [CrossRef] [PubMed]

33. Grima, J.; Wong, C.C.; Zhu, L.J.; Zong, S.D.; Cheng, C.Y. Testin secreted by Sertoli cells is associated with the cell surface, and its expression correlates with the disruption of Sertoli-germ cell junctions but not the inter-Sertoli tight junction. J. Biol. Chem. 1998, 273, 21040-21053. [CrossRef]

34. Grima, J.; Zhu, L.; Cheng, C.Y. Testin is tightly associated with testicular cell membrane upon its secretion by Sertoli cells whose steady-state mRNA level in the testis correlates with the turnover and integrity of inter-testicular cell junctions. J. Biol. Chem. 1997, 272, 6499-6509. [CrossRef]

35. Clark, A.M.; Griswold, M.D. Expression of clusterin/ sulfated glycoprotein-2 under conditions of heat stress in rat Sertoli cells and a mouse Sertoli cell line. J. Androl. 1997, 18, 257-263. [PubMed]

36. Sylvester, S.R.; Morales, C.; Oko, R.; Griswold, M.D. Localization of sulfated glycoprotein-2 (clusterin) on spermatozoa and in the reproductive tract of the male rat. Biol. Reprod. 1991, 45, 195-207. [CrossRef] [PubMed]

37. Fukuda, T.; Miyake, H.; Enatsu, N.; Matsushita, K.; Fujisawa, M. Seminal level of clusterin in infertile men as a significant biomarker reflecting spermatogenesis. Andrologia 2016, 48, 1188-1194. [CrossRef]

38. Bucci, L.R.; Meistrich, M.L. Effects of busulfan on murine spermatogenesis: Cytotoxicity, sterility, sperm abnormalities, and dominant lethal mutations. Mutat Res. 1987, 176, 259-268. [CrossRef]

39. Rey, R.; Mebarki, F.; Forest, M.G.; Mowszowicz, I.; Cate, R.L.; Morel, Y.; Chaussain, J.L.; Josso, N. Anti-Mullerian hormone in children with androgen insensitivity. J. Clin. Endocrinol. Metab. 1994, 79, 960-964.

40. Al Attar, L.; Noel, K.; Dutertre, M.; Belville, C.; Forest, M.G.; Burgoyne, P.S.; Josso, N.; Rey, R. Hormonal and cellular regulation of Sertoli cell antiMullerian hormone production in the postnatal mouse. J. Clin. Invest. 1997, 100, 1335-1343. [CrossRef]

41. Syed, V.; Gomez, E.; Hecht, N.B. Messenger ribonucleic acids encoding a serotonin receptor and a novel gene are induced in Sertoli cells by a secreted factor(s) from male rat meiotic germ cells. Endocrinology 1999, 140, 5754-5760. [CrossRef] [PubMed]

Publisher's Note: MDPI stays neutral with regard to jurisdictional claims in published maps and institutional affiliations.

(C) 2020 by the authors. Licensee MDPI, Basel, Switzerland. This article is an open access article distributed under the terms and conditions of the Creative Commons Attribution (CC BY) license (http://creativecommons.org/licenses/by/4.0/). 